\title{
Synthesis of Mercapto Ethyl Ester of Palm Fatty Acid Distillate
}

\author{
I Dewa Gede Arsa Putrawan ${ }^{1,}$, Adli Azharuddin ${ }^{1}$, Kartini Ratna Arum ${ }^{1}$, Dendy Adityawarman ${ }^{2}$, and Dicka Ar Rahim ${ }^{3}$ \\ ${ }^{1}$ Research Group on Chemical Product Design and Development, Institut Teknologi Bandung, Jl. Ganesha 10, Bandung, Indonesia \\ ${ }^{2}$ Research Group on Chemical Process Design and Development, Institut Teknologi Bandung, Jl. Ganesha 10, Bandung, Indonesia \\ ${ }^{3}$ Research Group on Energy and Processing System, Institut Teknologi Bandung, Jl. Ganesha 10, Bandung, Indonesia
}

\begin{abstract}
This research is aimed to study the synthesis of mercapto ethyl ester of fatty acid (MEFA) using palm fatty acid distillate (PFAD). The synthesis was carried out in a jacketed stirred vessel. Water as a byproduct was removed by using vacuum evaporation. p-Toluene sulfonic acid was used as catalyst. Temperature, mercaptoethanol excess, and catalyst amount were varied during the experiments. The variations ranges were $60-80^{\circ} \mathrm{C}, 5-25 \%$-mole, and 0.8-3.2\%-mole, respectively. The accomplishment of reaction was evaluated by measuring the mercaptan content and yield of MEFA. The mercaptan content and yield of MEFA were in the ranges of $6.4-8.0 \%$ and $64-86 \%$, respectively. It was found that mercaptan content and yield increased with temperature. The optimum temperature was found to be $70^{\circ} \mathrm{C}$, considering the mercaptan content, yield, and appearance of the product obtained. A full $2^{2}$ factorial design at a reaction temperature of $70^{\circ} \mathrm{C}$ showed that mercaptoethanol excess and catalyst amount had significant effects on the mercaptan content and yield of MEFA.
\end{abstract}

\section{Introduction}

Mercapto ethyl ester of fatty acid (MEFA) is used as raw material to produce organotin thermal stabilizers for poly vinyl chloride (PVC). Thermal stabilizer is added to PVC resin to prevent degradation due to heat treatment ([1]-[4]). Without thermal stabilizer, PVC degrades when heated even at $70^{\circ} \mathrm{C}$. The degradation process is also known as hydro-chlorination since it produces hydrogen chlorides. Thermal degradation changes PVC properties and color, from yellow to black, depending on the number of hydrogen chlorides liberated.

MEFA is produced from fatty acid and mercaptoethanol via the following reaction:

$$
\mathrm{RCOOH}+\mathrm{HSCH}_{2} \mathrm{CH}_{2} \mathrm{OH} \rightleftharpoons \mathrm{RCOOCH}_{2} \mathrm{CH}_{2} \mathrm{SH}+\mathrm{H}_{2} \mathrm{O}
$$

The above is a liquid phase, equilibrium reaction. The esterification products are called reverse-esters as they are derived from the reaction between mercapto-alcohols and fatty acids instead of between alcohols and mercapto-fatty acids [5]. Although it has long been mentioned by Litser and Hecker [6] and Kegule [7], studies on synthesis of MEFA are very limited. Wang et al. [8] investigated the synthesis of MEFA from commercial oleic acid and found that vacuum evaporation is the best method to remove water. They also found that the optimum reaction conditions include mercaptoethanol molar excess of $20 \%$, temperature range of $70 \sim 75^{\circ} \mathrm{C}$, and catalyst amount of $0.5 \%$ of total weight. Knežvić et al. [9] studied the reaction between mercaptoethanol and methacrylic acid and found that the esterification products consist of O-esters as main products and S-esters as side products.

For industrial applications, the common source of fatty acids for MEFA is tall oil fatty acid (TOFA) and the reverse-esters produced are called mercapto ethyl tallate (MET). TOFA is a byproduct of the wood pulp industry and resulted when pine wood chips are digested, under pressure, with an alkaline solution of sodium sulfate or an acidic solution of sodium sulfite ([10], [11]). The alkaline digestion of pine woods produces soap which changes to fatty acid on acidification. The obtained fatty acids are refined by distillation to remove rosins. The refined fatty acids are called TOFA with mainly consists of oleic and linoleic acids.

Recently, TOFA is difficult to obtain due to environmental problems. An alternative, therefore, needs to find. Putrawan et al. [12] have synthesized MEFA from rice bran oil fatty acid and found that fatty acid derived from rice bran oil could be converted into MEAL with satisfied results. Although rice bran oil is possible to be available in the form of free fatty acids, its acid value is not quite high to be used as raw material for MEFA. It needs hydrolysis as an additional preparation step before converted into MEFA.

Palm fatty acid distillate (PFAD) is a byproduct of palm oil refining industry. Fig. 1 shows the schematic of palm oil refining process. PFAD is produced during distillation to remove free fatty acids and odors after

Corresponding author: idewa@,che.itb.ac.id 
degumming and bleaching processes. PFAD mainly consists of free fatty acids. Like TOFA, PFAD is available in the form of free fatty acid and is produced as a byproduct. Its fatty acid composition, however, is different from that of TOFA. TOFA is dominated by unsaturated fatty acid, up to $90 \%$ ([10], [11], [13]) but PFAD has comparable contents in unsaturated and saturated fatty acids. PFAD is currently used by soap and fuel industries ([14], [15]).

This paper is aimed to study the utilization of PFAD as a substitute for TOFA in the production of MEFA as raw materials for PVC thermal stabilizers. The reaction was carried out in a batch stirred vessel under vacuum. The varied variables included temperature, mercaptoethanol molar excess and catalyst amount. The reaction performances were evaluated by measuring the mercaptan contents and yields of the product, which is named mercapto ethyl palmate (MEP) in this paper.

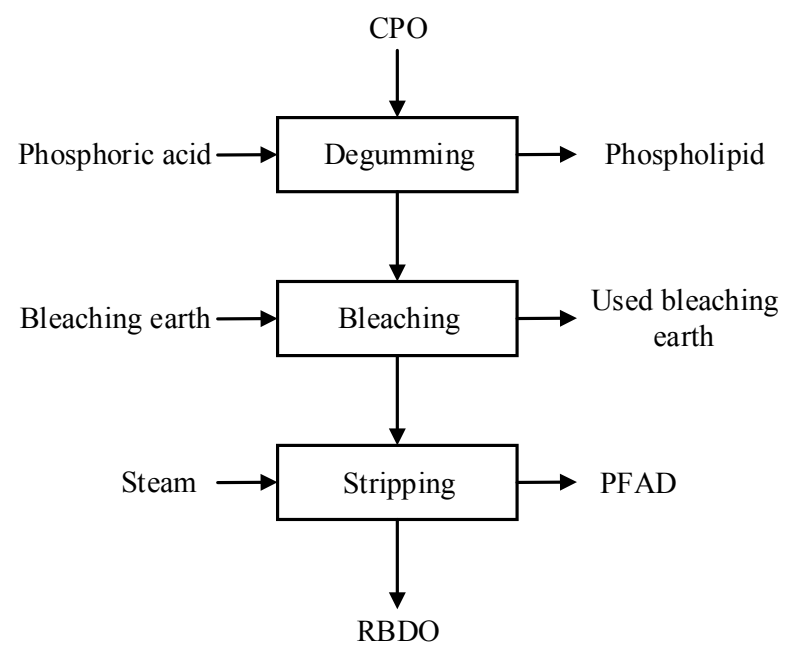

Fig. 1. Palm oil refining process.

\section{Experiments}

\subsection{Materials}

PFAD was obtained from a local palm oil refinery. Mercaptoethanol was purchased from Merck (>99\% purity) and para-toluene sulfonic acid (pTSA) as catalyst from Fluka ( $>98 \%$ purity) and used as accepted.

\subsection{Procedures}

A batch jacketed glass beaker with a capacity of $1 \mathrm{~L}$ was used as a reactor. The top of the reactor was connected to a vacuum condenser. The temperature of the reaction mixture was controlled by circulating hot water with controlled temperature. The apparatus was arranged as shown in Fig. 2. PFAD and mercaptoethanol were mixed in the reactor and stirred rigorously by using a magnetic stirrer. After the reaction temperature achieved the desired value, catalyst was then added into the reactor. The reactor was vacuumed, started at $200 \mathrm{mmHg}$ and decreased $50 \mathrm{mmHg}$ at every 30 minutes. At the end of the reaction, the reactor was heated and hold at $90^{\circ} \mathrm{C}$ for 30 minutes. The product obtained was filtered, weighted for yield determination and sampled for measuring mercaptan content and acid value.

A full $2^{\mathrm{k}}$ factorial design was applied to study the effects of mercaptoethanol excess and catalyst amount on the yield and mercaptan content of the product. The levels of each factor are shown in Table 1.

Table 1. Factor levels.

\begin{tabular}{|c|l|c|c|}
\hline$\#$ & \multicolumn{1}{|c|}{ Factor } & - & + \\
\hline 1 & Mercaptoethanol excess (\%-mole) & 5 & 25 \\
\hline 2 & Catalyst amount (\%-mole) & 0,8 & 3,2 \\
\hline
\end{tabular}

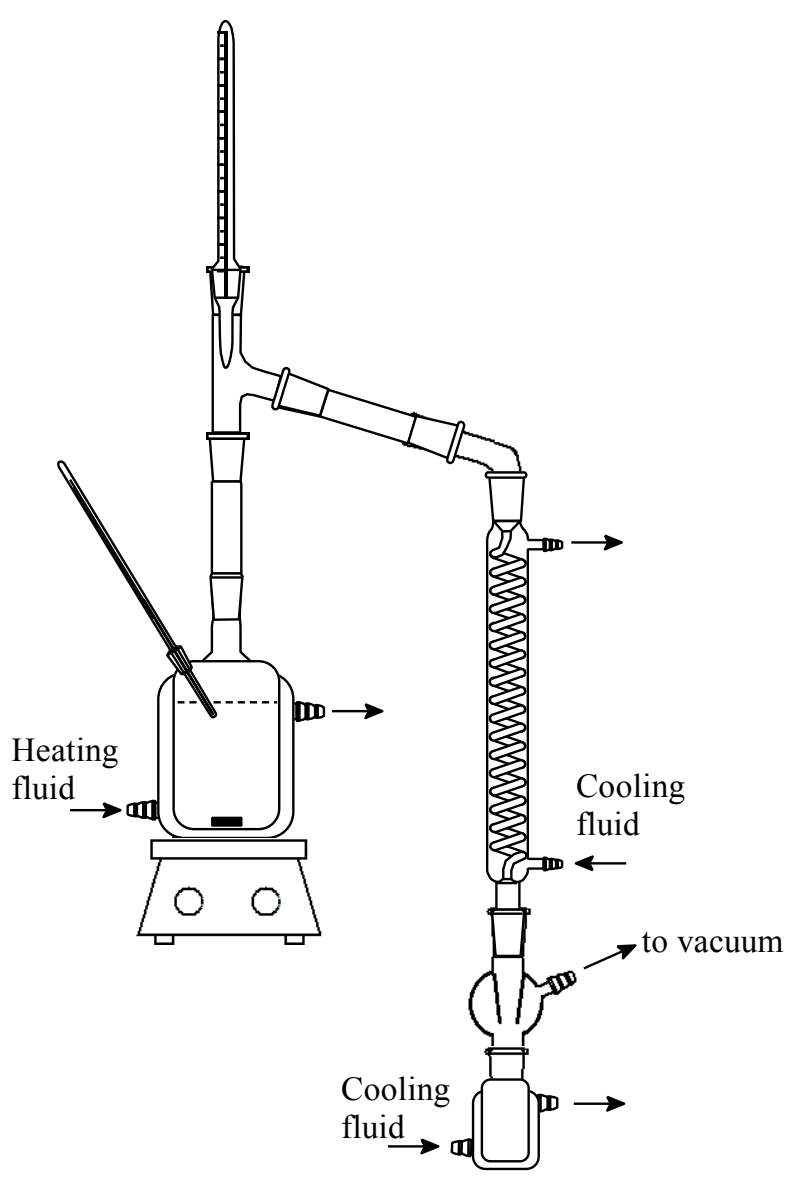

Fig. 2. Schematic of apparatus.

\subsection{Analysis}

Acid number was determined by direct titration (with $\mathrm{KOH}$ solution) of $1 \mathrm{~g}$ sample dissolved in $10 \mathrm{ml}$ of neutral ethanol in presence of phenolphthalein as indicator. The end points for the esterification products were not clear by observing color. Because of that, the $\mathrm{pH}$ of solution during titration was also monitored using a YSI pH meter pH100 model. The $\mathrm{pH}$ curves obtained was utilized to determine titration end points. Saponification value was determined using $\mathrm{KOH}$ solution under reflux followed by titration using $\mathrm{HCl}$. 
Iodine value was determined using Wijs method. Titer value was determined according to AOAC Official Method 942.18. The mercaptan contents were determined by iodine titration [16]. IR Spectra was measured by a Shimadzu IR-Prestige-21 Spectrophotometer.

\section{Results}

\subsection{PFAD characters}

The PFAD sample used had acid, saponification, and iodine values of $184 \mathrm{mg} \mathrm{KOH} / \mathrm{g}, 207 \mathrm{mg} \mathrm{KOH} / \mathrm{g}, 54 \mathrm{mg}$ $\mathrm{I}_{2} / \mathrm{g}$, respectively. As expected, the acid value was high showing the high content of free fatty acid. The saponification value is higher than the acid value, indicating that PFAD still contains neutral oil. The contents of main fatty acids, are given in Table 2 which also gives typical ranges for TOFA. The titer of PFAD used here was found to be $47^{\circ} \mathrm{C}$. It is solid at room temperature. PFAD contains about the same portions of saturated and unsaturated fatty acids. The saturated fatty acids of PFAD are mainly palmitic and stearic acids having melting points of $63^{\circ} \mathrm{C}$ and $70^{\circ} \mathrm{C}$, respectively ([11]). On the other hand, TOFA is approximately $90 \%$ unsaturated fatty acid, mainly oleic and linoleic acids having melting points of $16^{\circ} \mathrm{C}$ and $-5^{\circ} \mathrm{C}$, respectively ([11]). These are the reasons for PFAD to be solid and for TOFA to be liquid at room temperature.

Table 2. Composition of fatty acids.

\begin{tabular}{|l|c|c|c|c|}
\hline \multicolumn{1}{|c|}{ Fatty acid } & $\mathrm{C}_{16,0}$ & $\mathrm{C}_{18,0}$ & $\mathrm{C}_{18,1}$ & $\mathrm{C}_{18,2}$ \\
\hline PFAD (this work) & 33 & 6 & 31 & 15 \\
\hline TOFA ([1]) & \multicolumn{2}{|c|}{2,5} & $30-46$ & $36-45$ \\
\hline
\end{tabular}

\subsection{MEFA characters}

Fig. 3 shows the IR spectra of mercaptoethanol and PFAD. Mercaptoethanol showed stretching $\mathrm{OH}$ and $\mathrm{SH}$ frequencies at 3357 and $2557 \mathrm{~cm}^{-1}$, respectively. PFAD, as carboxylic acids, showed a characteristic peak at 1709 $\mathrm{cm}^{-1}$ representing $\mathrm{C}=\mathrm{O}$ bond. The stretching $\mathrm{OH}$ frequency was showed as a broad band in the range of 2500 300 $\mathrm{cm}^{-1}$. A peak at $2924 \mathrm{~cm}^{-1}$ representing a double bond $\mathrm{C}=\mathrm{CH}$, indicating the existence of unsaturated fatty acids. Fig. 4 shows the IR spectra of MEP. The IR spectra obtained revealed the characteristic peaks for MEFA structure, specifically at $2994 \mathrm{~cm}^{-1}$, $2923 \& 2853 \mathrm{~cm}^{-1}, 2570 \mathrm{~cm}^{-1}, 1740 \mathrm{~cm}^{-1}$ and $1235 \mathrm{~cm}^{-1}$, for the functional groups of $\mathrm{C}=\mathrm{CH}, \mathrm{CH}_{2}, \mathrm{SH}, \mathrm{C}=\mathrm{O}$, and $\mathrm{CO}$, respectively. Compared to the spectra of mercaptoethanol, the formation of $\mathrm{SH}$ functional group was found at $2570 \mathrm{~cm}^{-1}$. The $\mathrm{OH}$ peak still appeared but much shorter. It is due to the formation of S-ester in which the mercaptan site of mercaptoethanol reacted with the acid site of PFAD. Fig. 4 also shows the IR spectra of commercial MET. The IR spectra of MEP and MET are found to be identical. The peak for a double bond can be seen more clearly in the spectra of MET than that of MEP. It was caused by the high content of unsaturated fatty acids in TOFA. Compared to PFAD, the peak for $\mathrm{C}=\mathrm{CH}$ in $\mathrm{MEP}$ became weaker. This occurred as a part of double bound experience thiol-ene reaction with mercaptan ([17]). This side reaction is also possible to occur.
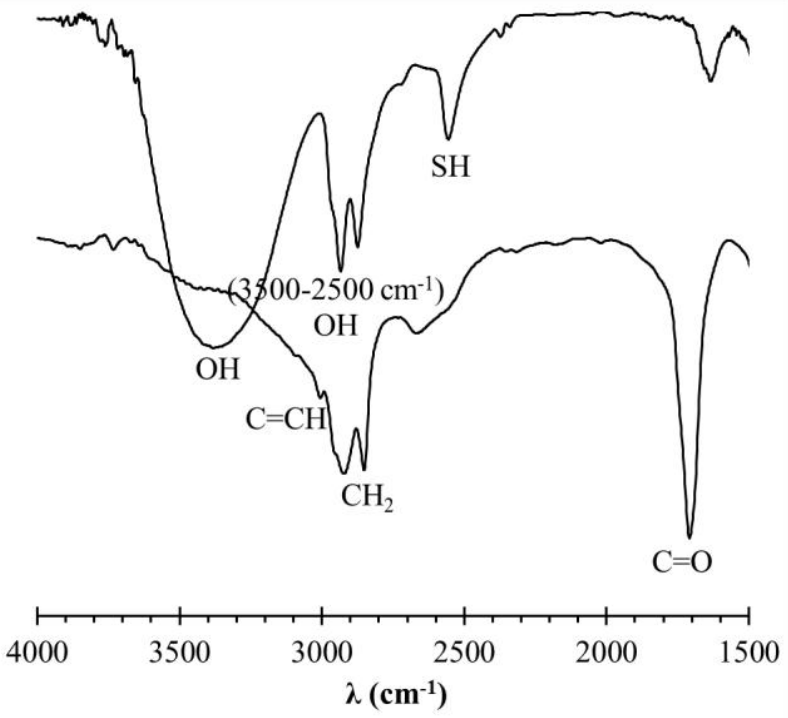

Fig. 3. IR spectra of ME and PFAD.

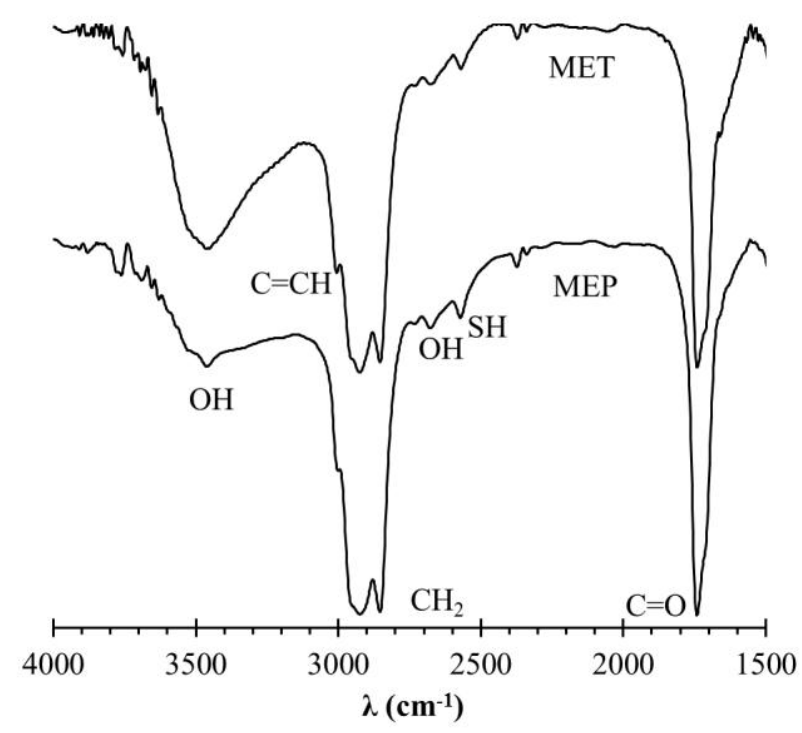

Fig. 4. IR spectra of ME and PFAD.

The product consisted of solid and liquid phases. Compared to PFAD, a decrease in titer was found. The addition of mercaptan functional group decreased melting point so that the product obtained was not totally solid at room temperature. In contrast, most of the product was liquid. It is commonly known that esterification lowered melting point. Palmitic acid, for example, has a melting point of $63^{\circ} \mathrm{C}$ but its methyl ester has a melting point of $31^{\circ} \mathrm{C}$ ([11]). Such decrease in melting point also found in the formation of reverse- 
ester. It occurs because the hydrogen bond of mercaptan is weak. The hydrogen bond of carboxylic acid, however, is strong.

\subsection{Effects of temperature}

Fig. 5, Fig. 6, and Fig. 7 show the effects of temperature on acid value, mercaptan content, and yield of MEFA. The measurement of acid value in MEFA to represent the residual fatty acid is not accurate since mercaptan also reacts with strong base. However, it could be used as a rough indicator to show significant decreases in fatty acid content have occurred, compared to PFAD.

Acid value decreased with temperature but mercaptan content and yield increased with temperature. Increasing temperature shifted the reaction to the product side as the higher temperature gives the molecules more kinetic energy. This means that the molecules move faster and be more likely to collide and to react successfully. In addition, increasing the temperature of reaction increased the volatility of water as a byproduct. When water evaporate faster, the reaction will shift to the product side. In the same reaction time, more product will be obtained at higher temperature.

The theoretical mercaptan content is $9.7 \%$ which corresponds to a yield of $100 \%$. The mercaptan content found here was in the range of $7 \%$ to $8 \%$, lower than the theoretical mercaptan content. About the same maximum mercaptan content was also found by Wang et al [8] using oleic acid. It was due the formation of $\mathrm{S}$ ester through the following reaction ([9], [18], [19]).

\section{$\mathrm{RCOOH}+\mathrm{HSCH}_{2} \mathrm{CH}_{2} \mathrm{OH} \rightarrow \mathrm{RCOSCH}_{2} \mathrm{CH}_{2} \mathrm{OH}+\mathrm{H}_{2} \mathrm{O}$}

Mercaptoethanol contains two active sites, i.e., mercaptan and hydroxyl. However, hydroxyl is more active than mercaptan. MEFA (O-ester) is formed when the hydroxyl site of mercaptoethanol reacts with the carboxyl site of fatty acid. S-ester is formed when the mercaptan site of mercaptoethanol reacts with the carboxyl site of fatty acid. With a strong acid as catalyst, such as pTSA, the formation of S-ester could not avoided because strong acids have limited selectivity. The formation of this side product has limited the mercaptan content and yield of MEP.

Organotin thermal stabilizers stabilize PVC by binding the escaping hydrochloric acid [1]. They substitute unstable chlorine atoms in the polymer chain and prevent the formation of polyene. The sulfur site of MEFA has important role in stabilizing PVC. When neutralizing the hydrochloric acid, it will be attached onto polyene sequences and thereby disrupting the conjugated double bond system and improve the color of the PVC object. The higher the mercaptan content of MEFA the better for MEFA to use as raw materials for organotin stabilizers. As can be seen, the highest mercaptan content was obtained at $80^{\circ} \mathrm{C}$. However, MEP obtained at this temperature solidified after aging. The solid found in MEPs which were synthesized at $60^{\circ} \mathrm{C}$ and $70^{\circ} \mathrm{C}$ could be easily melted by heating them. These solids were the saturated fractions of MEP. A part of solid found in MEP obtained at $80^{\circ} \mathrm{C}$ could not be melted and left as precipitates. Precipitates were also found by Wang et al [8], even using oleic acid, an unsaturated acid, at temperatures $80^{\circ} \mathrm{C}$ or above. It might be caused by the formation of polymers. The thiol-ene reaction between thiol and unsaturated bonds of oleic acid is a polymerization reaction [20]. Unsaturated fatty acids can also undergo self-condensation reactions to form high molecular weight dibasic and polybasic acids [21]. Thus, $70^{\circ} \mathrm{C}$ was considered as the optimum temperature for PFAD which is in the range of optimum temperature found by Wang et al. [8].

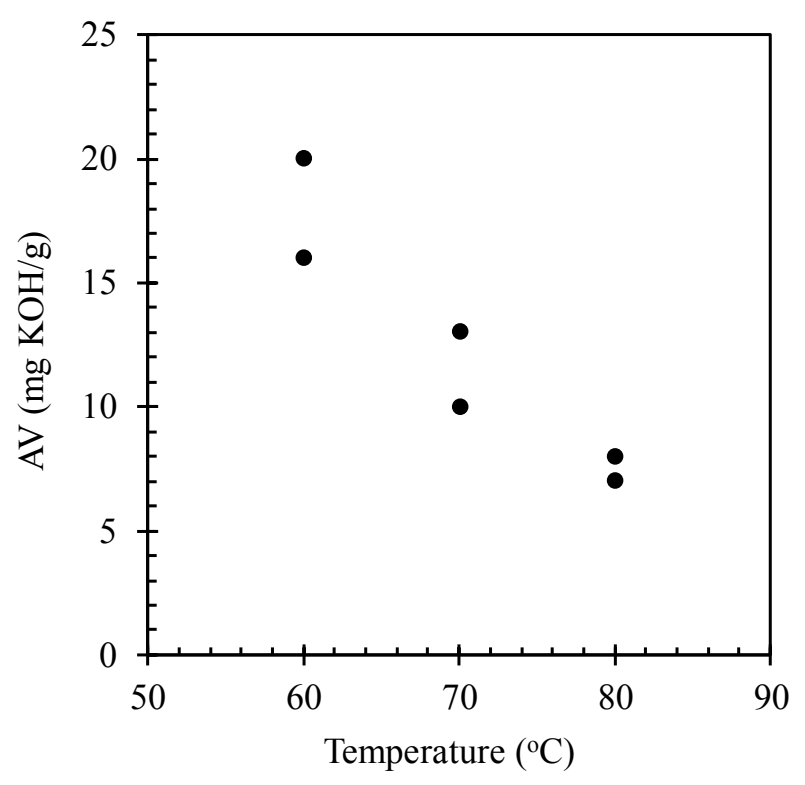

Fig. 5. Effect of temperature on acid value.

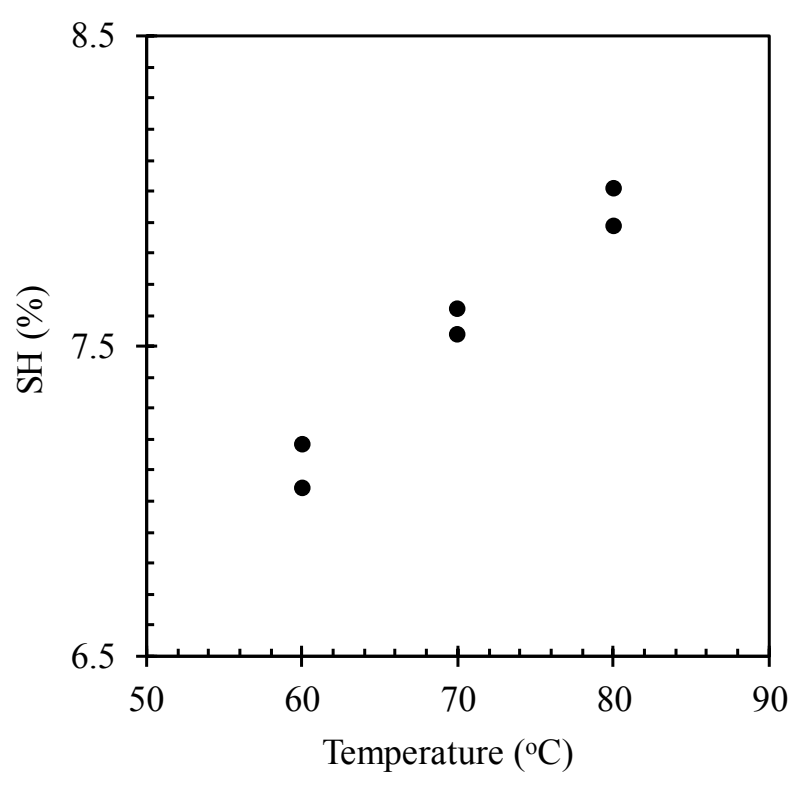

Fig. 6. Effect of temperature on mercaptan content.

\subsection{Effects of mercaptoethanol and catalyst}

A full $2^{2}$ factorial design with center points was used to study the effects of mercaptoethanol excess and catalyst 
amount on the mercaptan content and yield of MEFA. The effects of catalyst amount and mercaptoethanol excess on these two responses are presented in Fig. 8 and Fig. 9, respectively. Both mercaptoethanol excess and catalyst amount had positive effects on mercaptan and yield. Paying attention to the slopes of response lines, Fig. 8 at a glance shows that mercaptoethanol excess and catalyst amount had no interaction effect. On the other hand, Fig. 9 shows that an interaction occurred between mercaptoethanol excess and catalyst amount.

Table 3 and Table 4 present the analysis of factorial designs for mercaptan content and yield as responses, respectively. In general, a model for relating responses and factors can be written as ([22]):

$$
y=\beta_{o}+\beta_{1} \cdot x_{1}+\beta_{2} \cdot x_{2}+\beta_{12} \cdot x_{1} \cdot x_{2}
$$

where $\mathrm{y}$ is response, $\mathrm{x}$ is factor, and $\beta$ is parameter.

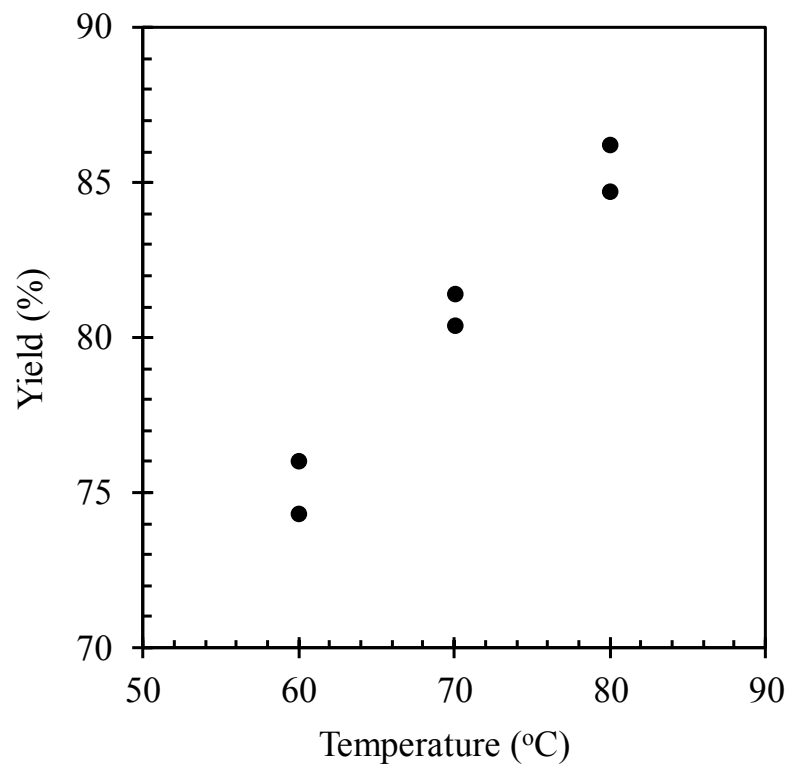

Fig. 7. Effect of temperature on yield.

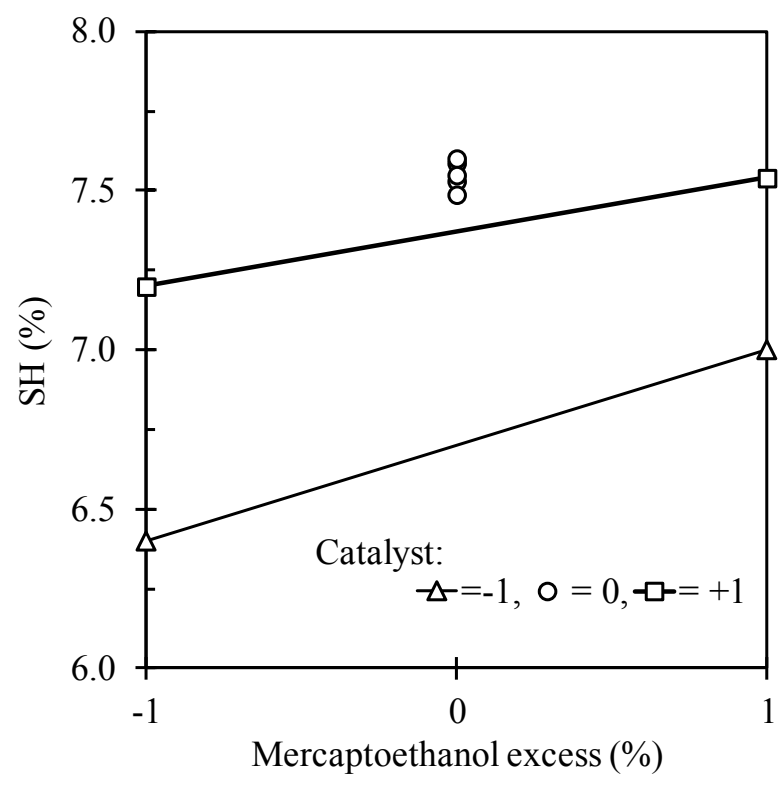

Fig. 8. Effects of mercaptoethanol excess and catalyst amount on mercaptan content.

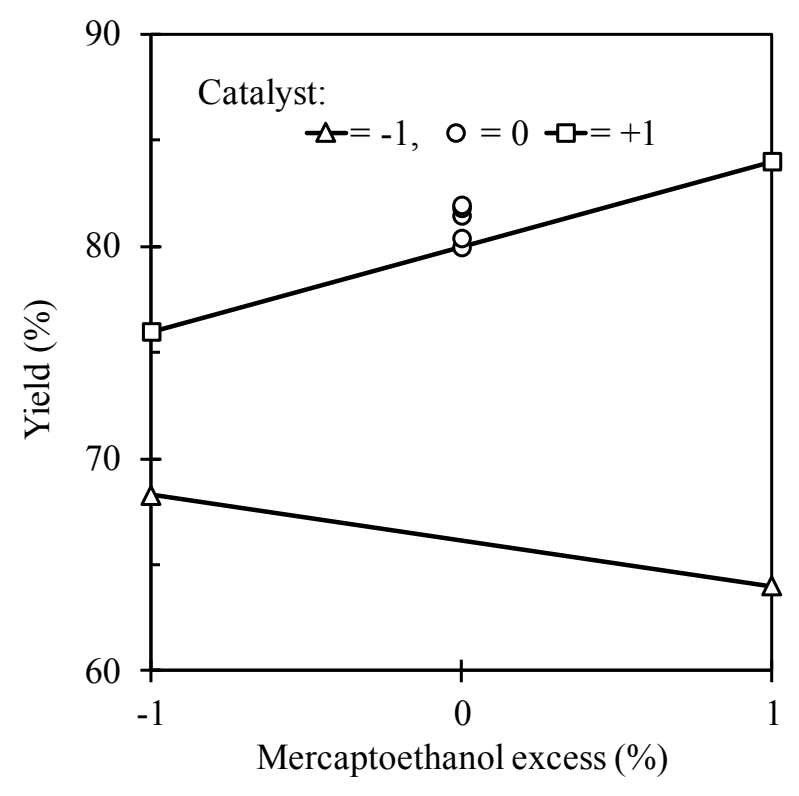

Fig. 9. Effects of mercaptoethanol excess and catalyst amount on yield.

The coefficients of the model in equation (1) are confined by the following confidence intervals:

$$
C I_{(\beta i)}=\beta_{i} \pm t_{n-1} s / V_{n}
$$

where $t_{n-1}$ is $t$ distribution, $s$ is standard deviation, and $n$ is degree of freedom. From the center point data, standard deviations for mercaptan and yield were found to be 0.04 and 0.89 , with four degrees of freedom. For a confidence level of $95 \%$, the confidence intervals for mercaptan content and yield are given bellow.

Mercaptan content:

$$
C I_{(\beta i)}=\beta_{i} \pm 0.06
$$

Yield:

$$
C I_{(\beta i)}=\beta_{i} \pm 1.10
$$

Table 3. Analysis of factorial design for mercaptan content.

\begin{tabular}{|c|c|c|c|c|}
\hline Run & $\mathrm{M}(\%)$ & $\mathrm{C}(\%)$ & $\mathrm{M}^{*} \mathrm{C}$ & $\mathrm{SH}(\%)$ \\
\hline 1 & -1 & -1 & 1 & 6.40 \\
\hline 2 & 1 & -1 & -1 & 7.00 \\
\hline 3 & -1 & 1 & -1 & 7.20 \\
\hline 4 & 1 & 1 & 1 & 7.54 \\
\hline 5 & 0 & 0 & 0 & 7.53 \\
\hline 6 & 0 & 0 & 0 & 7.49 \\
\hline 7 & 0 & 0 & 0 & 7.59 \\
\hline 8 & 0 & 0 & 0 & 7.60 \\
\hline 9 & 0 & 0 & 0 & 7.55 \\
\hline$\Sigma(-)$ & 13.60 & 13.40 & 14.20 & \\
\hline$\Sigma(+)$ & 14.54 & 14.74 & 13.94 & \\
\hline Effect & 0.47 & 0.67 & -0.12 & \\
\hline
\end{tabular}


Table 4. Analysis of factorial design for yield.

\begin{tabular}{|c|c|c|c|c|}
\hline Run & $\mathrm{M}(\%)$ & $\mathrm{C}(\%)$ & $\mathrm{M} * \mathrm{C}$ & $\mathrm{Y}(\%)$ \\
\hline 1 & -1 & -1 & 1 & 68.3 \\
\hline 2 & 1 & -1 & -1 & 64.0 \\
\hline 3 & -1 & 1 & -1 & 76.0 \\
\hline 4 & 1 & 1 & 1 & 84.0 \\
\hline 5 & 0 & 0 & 0 & 80.0 \\
\hline 6 & 0 & 0 & 0 & 80.4 \\
\hline 7 & 0 & 0 & 0 & 81.5 \\
\hline 8 & 0 & 0 & 0 & 81.8 \\
\hline 9 & 0 & 0 & 0 & 82.0 \\
\hline$\Sigma(-)$ & 144.30 & 132.30 & 140.00 & \\
\hline$\Sigma(+)$ & 148.00 & 160.00 & 152.30 & \\
\hline Effect & 1.85 & 13.85 & 6.15 & \\
\hline
\end{tabular}

It was found that both mercaptoethanol excess and catalyst amount as single factors significantly affected mercaptan content and yield. The interaction factor between mercaptoethanol excess and catalyst amount had no significant effects on mercaptan content but had significant effects on yield. The models for mercaptan content ( $\mathrm{SH})$ and yield $(\mathrm{Y})$, therefore, are given as:

$$
\begin{gathered}
S H=7.03+0.29 M+0.26 C \\
Y=72.40+1.86 M+6.70 C+3.05 M C
\end{gathered}
$$

where $\mathrm{M}$ and $\mathrm{C}$ stand for mercaptoethanol excess and catalyst amount, respectively, in coded factors.

Higher mercaptoethanol excess and higher catalyst amount increased mercaptan content and yield. This indicated that increasing mercaptoethanol or catalyst amount shifts the reaction to the MEFA side. Increasing mercaptoethanol means increasing reactant. For equilibrium reaction, this will shift the reaction toward the product side. As hydroxyl is more active than mercaptan, this also means increasing the possibility for the formation of O-ester, i.e., MEP in this case. An increase in MEP was observed as an increase in mercaptan content and yield. The nucleophilic acyl substitution of carboxylic acids with alcohols proceeds via two steps [18]: the attack of the alcohol's electronrich oxygen atom on the electron-deficient carbonyl carbon, forming a tetrahedral intermediate with a delocalized charged transition state, and the loss of the carboxylic acid's -OH leaving group, resulting in the esterified carbonyl group and water. Increasing catalyst amount increased the rate of reaction steps. As mentioned earlier, reaction pressure was decreased gradually. As each pressure was hold in the same time interval, higher reaction rate resulted in higher yields. Mercaptan content also increased with catalyst amount because pTSA as catalyst favored the formation of Oester, as mentioned by Knežvić et al [9]. F-test showed that the effects of mercaptoethanol excess and catalyst amount exhibited a curvature. A central composite design is therefore necessary to elaborate the models.

\section{Conclusions}

Mercapto ethyl ester (reverse-ester) of palm fatty acid distillate has been synthesized in a jacketed stirred vessel under vacuum using pTSA as catalyst. It was found that mercaptan content and yield increased with temperature. A full $2^{2}$ factorial design showed that catalyst amount and mercaptoethanol excess increased mercaptan content and yield significantly. The mercaptan content and yield of the reverse-ester obtained were in the ranges of 6.4$8.0 \%$ and $64-86 \%$, respectively.

This research was supported by the Indonesian Estate Crop Fund for Palm Oil (BPDPKS) under GRS 2016.

\section{References}

1. M. Schiller, PVC Additives (Hanser Publisher, Munich, 2015).

2. E. Arkiş, D. Barköse, Polymer Degrad. and Stability, 88, 46-51 (2005).

3. W. H. Starnes, Procedia Chem., 4, 1-10 (2012).

4. S. Hope, I. Sewell, South African Vinyls Association Conference, Johannesburg, South Africa (2014).

5. G. F. Beekman, L. R. Price, Eur Pat 0850987A1 (1999).

6. W. E. Leistner, A. C. Hecker, US Pat 2870182A (1959).

7. T. G. Kugele, US Paten 4120845 (1959).

8. A. Wang, J. Li, J. Li, X. Zhong, S. Long, Chinese Plastic Additives, 91 (1), 34-37 (2012).

9. M. Knežvić, L. Katsikas, I. G. Popović, Hem. Ind., 59(11-12), 321-323 (2005).

10. F. D. Gunstone, Chemistry of oils and fats (CRC Press, Oxford, 2004)

11. F. Shahidi, Bailey's Industrial Oil and Fat Products, Edible Oil and Fat Products: Chemistry, Properties, and Health Effects (John Wiley \& Sons, New Jersey, 2005).

12. I. D. G. A. Putrawan, D. K. Bestari, C. A. Wicaksana, Chemical Engineering Seminar (Parahyangan University, Bandung, 2016).

13. R. L. Logan, JAOCS, 56 (11), 777A-779A (1979).

14. N. H. Embong, G. P. Maniam, M. H. A. Rahim, K. T. Lee, D. Huisingh, J Clean. Prod., 116, 244-248 (2016).

15. A. G. M. Top, Lipid Technol., 22 (1), 11-13 (2010).

16. G. H. Jeffery, J. Bassett, J. Mendham, R. C. Denney, Vogel's Textbook of Quantitative Chemical Analysis, 5th edn (Longman Scientific \& Technical, England, 1989).

17. S. K. Sharma, A. Mudhoo, A Handbook of Applied Biopolymer Technology: Synthesis, Degradation and Applications (Royal Society of Chemistry, Rajasthan, India, 2011)

18. D. L. Compton, M. A. Jackson, JAOCS, 88, 17991805 (2011). 
19. P. E. Sonnet, G. G. Moore, Lipids 24(8), pp. 743745 (1989).

20. J. Samuelsson, M. Jonsson, T. Brinck, M. Johansson, J. Poly. Sci., 42(24), 6346-6352 (2004).

21. D. J. Anneken, S. Both, R. Christoph, G. Fieg, U. Steinberner, A. Westfechtel, Ullmann's Encyclopedia of Industrial Chemistry: Fatty Acid (Wiley-VCH Verlag GmbH \& Co, Weinheim, 2006).

22. M. C. Montgomery, Design and Analysis of Experiments (John Willey \& Sons, New York, 2001). 